Received: 5 October 2016

Accepted: 7 March 2017

Published online: 28 March 2017

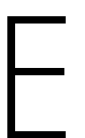

C N
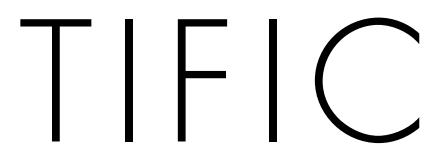

REP

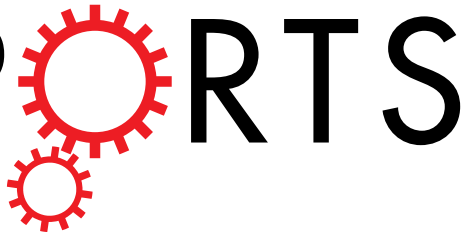

OPEN

\section{Hydration of Proton-conducting $\mathrm{BaCe}_{0.9} \mathrm{Y}_{0.1} \mathrm{O}_{3-\delta}$ by Decoupled Mass Transport}

\author{
Dae-Kwang Lim ${ }^{1}$, Ha-Ni Im ${ }^{1}$, Sun-Ju Song ${ }^{1} \&$ Han-III Yoo ${ }^{2}$
}

Mass relaxation profile of a perovskite-type oxide, $\mathrm{BaCe}_{0.9} \mathrm{Y}_{0.1} \mathrm{O}_{3-\delta}$, was studied to understand decoupled diffusion of oxygen and hydrogen species during hydration/dehydration. The mass relaxation measurements are performed by thermogravimetric analysis (TGA) under various humidity conditions (Dry, $\left.-3.0 \leq \log \left(\mathrm{pH}_{2} \mathrm{O} / \mathrm{atm}\right) \leq-1.6\right)$ at a constant oxygen partial pressure $\left(\log \left(p \mathrm{O}_{2} /\right.\right.$ atm $)=-1.00 \pm 0.01)$. The decoupled ions participated in hydration/dehydration reactions were proven to be at different ratios from the result introduced by the $8 R_{m}$ function. The enthalpy and entropy of non-stoichiometric hydration reaction, which considers each ratio of charge-carrier species, were $-144.7 \pm 3.7 \mathrm{~kJ} / \mathrm{mol}$ and $-147.8 \pm 3.2 \mathrm{~J} / \mathrm{mol} \cdot \mathrm{K}$, respectively.

Among many well-known perovskite proton-conducting materials, acceptor-doped barium cerate and barium zirconate $\left(\mathrm{BaCe}_{1-\mathrm{x}} \mathrm{M}_{\mathrm{x}} \mathrm{O}_{3-\delta}, \mathrm{BaZr}_{1-\mathrm{x}} \mathrm{M}_{\mathrm{x}} \mathrm{O}_{3-\delta} ; \mathrm{M}=\mathrm{Y}, \mathrm{Yb}\right)$ have been the most studied materials for application in practical solid-state devices, because they have high proton conductivities at intermediate temperatures (500$\left.800^{\circ} \mathrm{C}\right)^{1-5}$. The proton concentration ${ }^{6-8}$ and chemical diffusivity of water ${ }^{9-11}$ in these materials, as functions of thermodynamic parameters, have been investigated for their specimens exposed to sudden changes in water vapor content because of the functionality as solid electrolyte. However, in these proton conductors some recent reports, such as the electrical conductivity relaxation measurements showing a non-monotonic two-fold relaxation behavior ${ }^{12-14}$ and in situ optical absorption spectroscopy with impedance spectroscopy ${ }^{15}$, have demonstrated that in the p-type oxidizing regime the proton transport depends on the two decoupled ambipolar diffusivities of proton and hole $\left(\mathrm{OH}_{\mathrm{O}^{-}} h^{-}\right)$and $\left(V_{\mathrm{O}^{-}}-2 h^{\prime}\right)$ pairs. Accordingly, the decoupled mass- and charge-transport theory, which was earlier based on the chemical diffusion of water, has been successfully revised by Yoo et al. ${ }^{16}$.

The objective of this work is to prove the non-stoichiometric water diffusion by studying mass relaxation during hydration/dehydration process involving the decoupled diffusion via thermogravimetric analysis (TGA) for 10 -mol\% Y-doped $\mathrm{BaCeO}_{3}$ materials under various thermodynamic conditions. The mass relaxation experiments using TGA were uniquely performed to clearly confirm the reaction of decoupled diffusion of hydrogen and oxygen upon hydration and dehydration in a p-type conductor. The weight change experiments also allowed the calculation of the equilibrium constant of the overall nonstoichiometric water uptake reaction as the ratio of charge carrier concentrations based on the concentrations of decoupled hydrogen and oxygen.

\section{Theoretical background}

In the mass-relaxation, the chemical diffusion fluxes $J_{i}$ and $J_{v}$, from Supplementary equations (S5) and (S6), are oriented parallelly during hydration or dehydration. The overall weight change of the specimen can be represented as:

$$
\left(m-m_{0}\right) / V_{0}=\mathrm{w}_{i}\left(\bar{C}_{i}-C_{i, 0}\right)+\mathrm{w}_{v}\left(\bar{C}_{v}-C_{v, 0}\right)
$$

where $m_{0}$ is the initial specimen-mass at $t=0$, and $\mathrm{w}_{i}$ and $\mathrm{w}_{v}$ are the mass per unit concentration of protons and oxygen, respectively. Although the volume of sample $\left(V_{0}\right)$ may change under hydration or dehydration, it is assumed to remain constant because the overall difference may be negligible. The values for $\mathrm{w}_{i}$ and $\mathrm{w}_{v}$ are the molar weight of the carrier species, which are defined as $1 \mathrm{~g} / \mathrm{mol}$ and $16 \mathrm{~g} / \mathrm{mol}$, respectively when protons and oxygen ions are solely responsible for the mass-transfer.

The closed-form solution for hydration or dehydration is ref. 13:

${ }^{1}$ Department of Materials Science and Engineering, Chonnam National University, Gwangju, 61186, Republic of Korea. ${ }^{2}$ Department of Materials Science and Engineering, Seoul National University, Seoul, 08826, Republic of Korea. Correspondence and requests for materials should be addressed to S.-J.S. (email: song@chonnam.ac.kr) 


$$
\Delta m=m-m_{0}=\left(B_{i}+B_{v}\right)-B_{i} f\left(\tau_{i}\right)-B_{v} f\left(\tau_{v}\right)
$$

with

$$
\begin{gathered}
B_{i} \equiv \mathrm{w}_{i} V_{0}\left(C_{i, \infty}-C_{i, 0}\right) \\
B_{v} \equiv \mathrm{w}_{v} V_{0}\left(C_{v, \infty}-C_{v, 0}\right)
\end{gathered}
$$

The range of concentration of $k=i, v$ is $C_{k, 0} \leq \bar{C}_{k} \leq C_{k, \infty}$ for hydration and $C_{k, 0} \geq \bar{C}_{k} \geq C_{k, \infty}$ for dehydration.

The external equilibria are expressed, including the equilibrium constant of the hydration reaction in Supplementary equation (S3), by the following equations ${ }^{17,18}$ :

$$
\begin{gathered}
K_{1} ; \mathrm{H}_{2} \mathrm{O}+\mathrm{V}_{\mathrm{O}}^{\cdot}+\mathrm{O}_{\mathrm{O}}^{\times} \leftrightarrow 2 \mathrm{OH}_{\mathrm{O}} \\
K_{2} ; \mathrm{H}_{2} \mathrm{O}+2 \mathrm{~h}+2 \mathrm{O}_{O}^{\times} \leftrightarrow 2 \mathrm{OH}_{\mathrm{O}}^{\cdot}+\frac{1}{2} \mathrm{O}_{2}(g) \\
K_{3} ; \frac{1}{2} \mathrm{O}_{2}(g)+V_{O}^{\cdot} \leftrightarrow \mathrm{O}_{O}^{\times}+2 h
\end{gathered}
$$

The corresponding equilibrium constants are given by:

$$
\begin{gathered}
K_{1}=\frac{\left[\mathrm{OH}_{\mathrm{O}}\right]^{2}}{\left[\mathrm{~V}_{\mathrm{O}}^{*}\right] \cdot\left[\mathrm{O}_{\mathrm{O}}^{\times}\right] \cdot p \mathrm{H}_{2} \mathrm{O}} \\
K_{2}=\frac{\left[O \mathrm{OH}_{\mathrm{O}}^{\cdot}\right]^{2} \cdot p \mathrm{O}_{2}^{1 / 2}}{p^{2} \cdot p \mathrm{H}_{2} \mathrm{O} \cdot\left[\mathrm{O}_{\mathrm{O}}^{\times}\right]^{2}} \\
K_{3}=\frac{p^{2} \cdot\left[\mathrm{O}_{O}^{\times}\right]}{p \mathrm{O}_{2}^{1 / 2} \cdot\left[V_{O}^{*}\right]}
\end{gathered}
$$

The relationship of the equilibrium constants $K_{1}, K_{2}$, and $K_{3}$ can be expressed as:

$$
K_{1}=K_{2} \cdot K_{3}
$$

Defining a quantity $R_{m}$ as the reaction of the incorporation of hydrogen and oxygen for the hydration of the sample, or the reaction of the separation of these carriers for dehydration, the $R_{m}$ for mass relaxation upon water uptake can be derived from equations (3) and (4) as ref. 13:

$$
R_{m}=\frac{B_{i}}{B_{v}}=\frac{w_{i} \Delta c_{i}}{w_{v} \Delta c_{v}}
$$

$R_{m}$ has a value of $1 / 8$ when the reaction of water occurs by $K_{1}$ (equation (5)), which is directly proportional to $\mathrm{H}_{2} \mathrm{O}$. In the uptake of decoupled hydrogen and oxygen, the ratio of excess oxygen in the reaction $(x)$ is denoted as:

$$
x=\frac{1}{8 R_{m}}
$$

where $8 R_{m}$ is the ratio of the changes in the concentrations of hydrogen versus oxygen for a hydration reaction; it is equal to 1 when incorporating $\mathrm{H}_{2} \mathrm{O}$. The value of $x$ has three distinguishable regimes; 1 ) $x=1$ occurs with water, 2) $x<1$ occurs for an excess of protons, and 3) $x>1$ occurs for an excess of oxygen ions. The ratio of the concentrations of hydrogen and oxygen ions can be calculated with the parameter $x$ defined by the $K_{1}$ and $K_{2}$ (equation (6)) reactions. Therefore, the weight of the sample may be divided into the weight changes resulting from $K_{1}$ and $K_{2}$ as:

$$
\Delta m_{\text {total }}^{o}=x \cdot m_{K 1}+(1-x) \cdot m_{K 2}
$$

where $\Delta m_{\text {total }}^{o}, m_{K 1}$, and $m_{K 2}$ are the total weight change of the sample, weight change for the $K_{1}$ reaction, and weight change for the $K_{2}$ reaction, respectively. The weight change occurs by the $K_{2}$ reaction at $x=0$. Meanwhile, the weight change by the $K_{1}$ reaction occurs at $x=1$. For $x<1$, the reaction of the consumption of holes is dominant by the $K_{2}$ reaction; for $x>1$, the formation of holes is dominant by the $K_{3}$ (equation (7)) reaction. The overall nonstoichiometric water incorporation equation, combining $K_{1}$ and $K_{2}$, is denoted as: 


$$
\begin{aligned}
& K_{4} ; \mathrm{H}_{2} \mathrm{O}+x V_{O}^{\ddot{*}}+(2-x) \mathrm{O}_{O}^{\times}+(2-2 x) h \\
& \leftrightarrow 2 \mathrm{OH}_{\mathrm{O}}+\left(\frac{1-x}{2}\right) \mathrm{O}_{2}(g)
\end{aligned}
$$

The relationship between the variations in the concentration of each carrier and the measured weight change can be described as:

$$
\Delta[j]=\frac{\Delta m_{j} \cdot M_{s}}{M_{j} \cdot m_{s, 0}}
$$

where subscript $j$ denotes species $\mathrm{H}_{2} \mathrm{O}, \mathrm{O}$ (dry condition only) or $\mathrm{H}_{2} ; \Delta m_{j}$ is the weight change of the specimen by the $j$ species, $m_{s, 0}$ is the initial specimen weight, $M_{j}$ is the molar weight of the $j$ species and $M_{s}$ is the molecular formula weight of the specimen.

The changes in the concentration of charge carriers are calculated using equation (16) during hydration (or dehydration). The four independent equations relating variations in the concentration of charge carriers should be satisfied when weight change occurs by water using TGA, as shown in the $K_{4}$ reaction. The relationship between the structural elements under hydration at equilibrium is expressed below, using the changes in concentration of charge carriers causing weight change by the $K_{4}$ reaction. The signal proceeds in the opposite direction under dehydration conditions.

$$
\begin{gathered}
\Delta\left[\mathrm{OH}_{\mathrm{O}}^{\cdot}\right]=2 \cdot \Delta\left[\mathrm{H}_{2} \mathrm{O}\right] \\
\Delta\left[\mathrm{V}_{\mathrm{O}}^{\ddot{*}}\right]=-x \cdot \Delta\left[\mathrm{H}_{2} \mathrm{O}\right] \\
\Delta\left[\mathrm{O}_{\mathrm{O}}^{\times}\right]=(x-2) \cdot \Delta\left[\mathrm{H}_{2} \mathrm{O}\right] \\
\Delta p=(2 x-2) \cdot \Delta\left[\mathrm{H}_{2} \mathrm{O}\right]
\end{gathered}
$$

\section{Results and Discussion}

Mass relaxation upon hydration/dehydration. Figure la shows the weight change in dry $\left(p \mathrm{H}_{2} \mathrm{O}=4.0 \times 10^{-5} \mathrm{~atm}\right)$ and wet $\left(p \mathrm{H}_{2} \mathrm{O}=0.0063 \mathrm{~atm}\right)$ conditions as functions of temperature after measuring the reference zero point of the weight under $\mathrm{N}_{2}$. The weight difference between the wet and dry conditions at $1000^{\circ} \mathrm{C}$ indicates that it is caused by the reaction of $K_{4}$. From the weight difference between the maximum and minimum temperatures, the total weight changes are $1.211 \mathrm{mg}$ and $1.195 \mathrm{mg}$ in wet and dry conditions, respectively. In terms of the low-temperature region in wet conditions, it looks that protons do not escape the oxide and instead remain present in the solid. The weight increases in both dry and wet conditions with decreasing temperature, while oxygen forms by filling the oxygen vacancies from the $K_{3}$ reaction in dry conditions and the weight of oxide is increased by the $K_{4}$ reaction in wet conditions. In the second-order derivative of the weight change as a function of temperature, as shown Fig. $1 \mathrm{~b}$, the maximum negative slope change occurs at $\sim 460^{\circ} \mathrm{C}$ for dry conditions and the maximum positive slope change appears at $\sim 560^{\circ} \mathrm{C}$. The maximum point of the change in weight is at $500^{\circ} \mathrm{C}$ as the maximized weight change by the $K_{3}$ reaction. In wet conditions, the maximum negative and positive slope changes occur at $\sim 600^{\circ} \mathrm{C}$ and $\sim 770^{\circ} \mathrm{C}$, respectively. The maximum point of the change in weight is $\sim 670^{\circ} \mathrm{C}$, indicating that the weight change of the oxide appears most significantly under a given $p \mathrm{H}_{2} \mathrm{O}$ at this temperature. If the temperature increases above $670^{\circ} \mathrm{C}$, the magnitude of solubility of the water vapor reacting with the oxide is reduced.

The weight difference measured in dry and wet conditions is shown in Fig. 1c. The weight difference values indicate not only the largest differential of weights possibly combined into the oxide, but also the weight of water vapor incorporated for a given $\mathrm{pH}_{2} \mathrm{O}$ at each temperature. Because the weight change of the BCY10 sample occurs with significant dependence on the existing water vapor at $\sim 600^{\circ} \mathrm{C}$, the thermal expansion coefficient (TEC) of the hydration state is assumed the largest. In addition, the value can be inferred to indicate the dependence of temperature on $\mathrm{pH}_{2} \mathrm{O}$, because it is the difference in weight between the hydrated and dried specimens. Similar to these predictions, using in-situ high-temperature XRD equipment, Anderson et al. ${ }^{19}$ reported on the proton-conductor material $\mathrm{BaCe}_{0.8} \mathrm{Y}_{0.2} \mathrm{O}_{2.9}$ (BCY20) that the volume of a specimen rapidly changed near $600^{\circ} \mathrm{C}$ at $p \mathrm{H}_{2} \mathrm{O}=1 \times 10^{-4}$ atm and that the temperature range in which the volume change occurred was increased with increasing $\mathrm{pH}_{2} \mathrm{O}$.

To confirm the reaction of hydration with the sample as a direct proportion $\left(\mathrm{H}_{2} \mathrm{O}\right)$ from decoupled proton and oxygen, $8 R_{m}$ as a function of temperature is shown in Fig. $1 \mathrm{~d}$ using $B_{k}(k=i, v)$ in equation (2), which is calculated from the mass relaxation. As expressed in equation (12), $8 R_{m}$ is always equal to 1 if the stoichiometric hydration or dehydration reaction occurs by $K_{1} .8 R_{m}$ denotes the rate of concentration change in the reaction involving hydrogen $\left(\mathrm{H}_{2}\right)$ and oxygen $(\mathrm{O})$ when different partial pressures of water vapor are applied to the oxide. As seen in Fig. 1d, because $8 R_{m}$ is below 1 in the region of $600-700^{\circ} \mathrm{C}$, oxygen is incorporated more into the oxide in the hydration reaction than hydrogen is. $8 R_{m}$ is slightly greater than 1 above $750^{\circ} \mathrm{C}$ in the high-temperature region, indicating that hydrogen becomes more involved in the hydration reaction to excess. The ratio of the concentration of hydrogen and oxygen reacting at $\sim 1000^{\circ} \mathrm{C}$ is almost $2: 1$, because the reaction may occur by the $K_{1}$ mode with the extremely low hole concentration. Note that this value does not represent the absolute value of the 

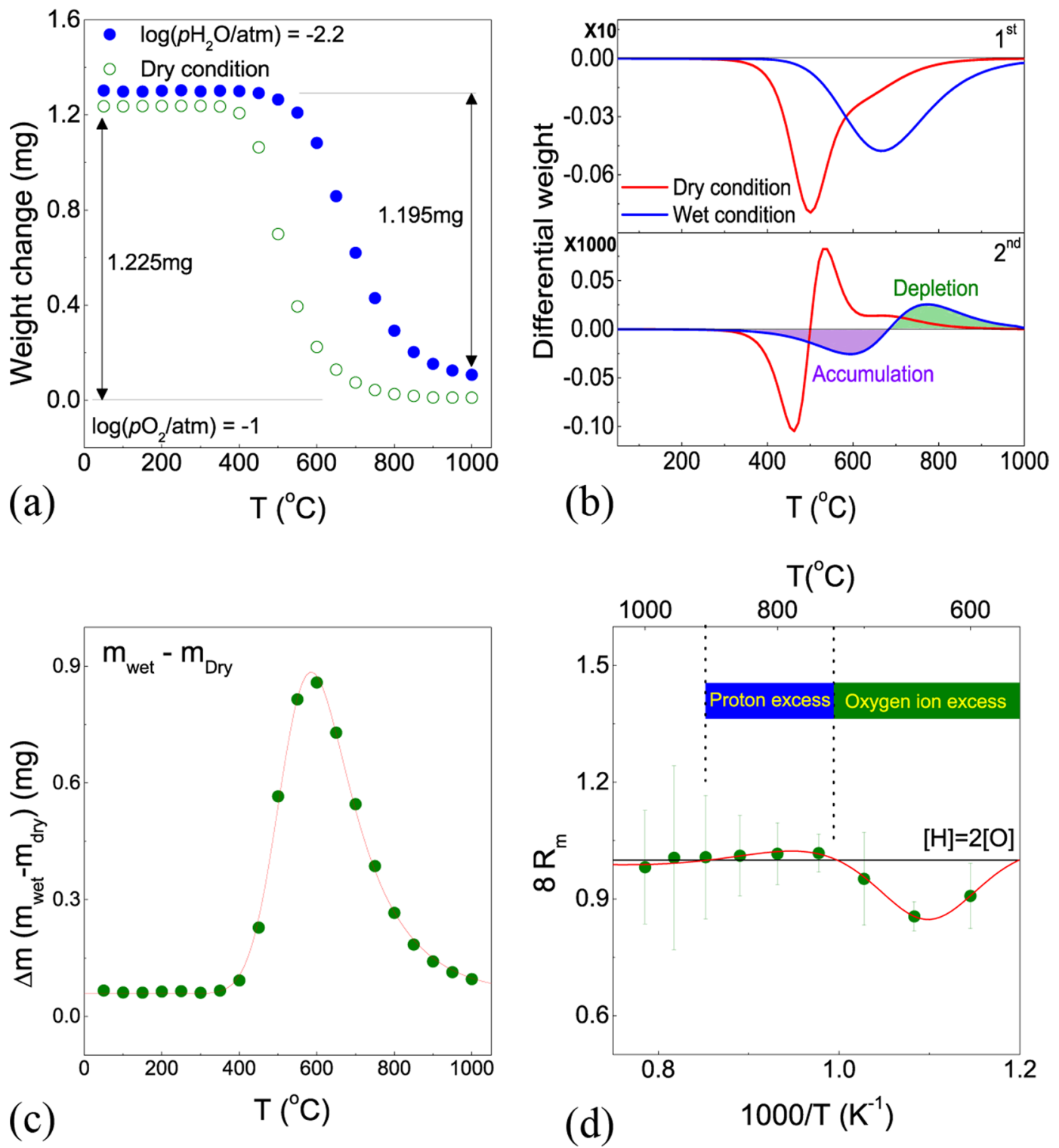

Figure 1. (a) Weight change, (b) differential weight of BCY10, (c) difference in weight between dry $\left(p \mathrm{H}_{2} \mathrm{O}=4.0 \times 10^{-5} \mathrm{~atm}\right)$ and wet $\left(p \mathrm{H}_{2} \mathrm{O}=0.0063 \mathrm{~atm}\right)$ conditions, and (d) relative reaction concentrations, $\mathrm{R}_{\mathrm{m}}$, using $B_{k}(k=i, v)$ from TGA mass relaxation upon hydration as functions of temperature.

solubility, indicating the ratio of the hydrogen and oxygen. From this result, the actual ion concentration participating in the hydration reaction has clearly different ratios with dependences on the thermodynamic conditions.

Non-stoichiometry and concentration of charge carrier. The stoichiometric value $\left(\mathrm{ABO}_{2.95}\right)$ is assumed to exist in the dry $\mathrm{N}_{2}$ atmosphere at $1000^{\circ} \mathrm{C}$; an oxygen non-stoichiometric value of 2.9503 is measured at $p \mathrm{O}_{2}=0.1 \mathrm{~atm}$ at $1000^{\circ} \mathrm{C}$. Considering the main point defects of $p$-type $\mathrm{BCY} 10$ under wet conditions, the total charge-neutral conditions from Supplementary equation (S4) can be represented as:

$$
2\left[V_{O}^{*}\right]+\left[\mathrm{OH}_{\mathrm{O}}^{\cdot}\right]+p=\left[Y_{\mathrm{Ce}}^{\prime}\right]
$$

Oishi et al. ${ }^{20}$ reported that the ionic valence of $\mathrm{Ce}^{4+}$ did not change with variations in temperature or $p \mathrm{O}_{2}$ in $10 \mathrm{~mol} \%$ neodymium-doped $\mathrm{BaCeO}_{3}$ material at p-type conducting regime. Thus, the weight change with temperature at a fixed $p \mathrm{O}_{2}$ value is attributed only to redox reactions without involving cation reduction at lattice. Figure 2 shows the variations of concentration of each charge carrier species under dry and wet conditions. After the proton concentration sharply increases with a decrease in temperature, it tends to converge at lower temperatures. By contrast, the oxygen vacancy concentration is decreased by the reaction $K_{4}$, but the concentration of holes tends to increase slightly at temperatures below $700^{\circ} \mathrm{C}$. The concentrations of the charge carriers satisfy the neutral condition of the hydration reaction expressed in equation (21) when the doping content is equal to 0.1 . In Fig. $2 \mathrm{~b}$, the concentrations of charge carriers change rapidly within the temperature range of $600-800^{\circ} \mathrm{C}$. 
(a)

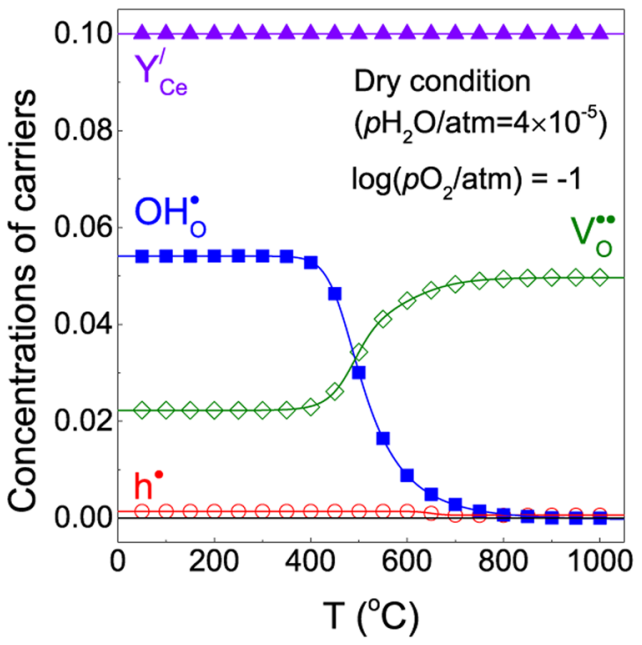

(b)

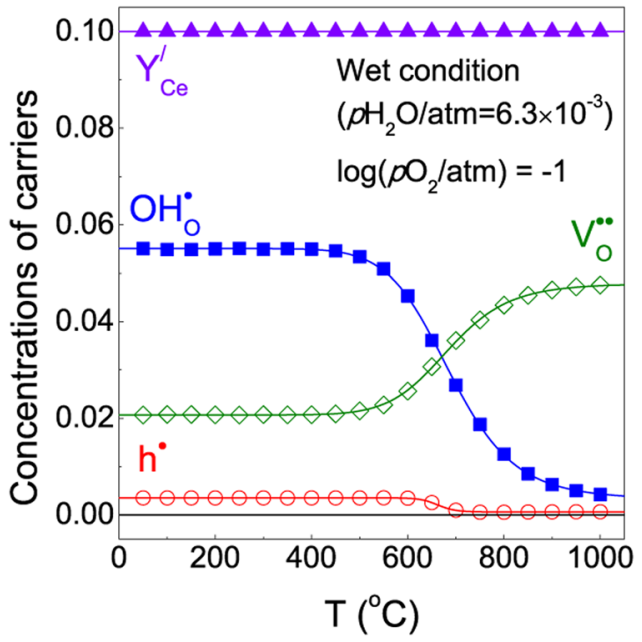

Figure 2. Concentrations of charge carriers under (a) dry condition $\left(p \mathrm{H}_{2} \mathrm{O}=4.0 \times 10^{-5} \mathrm{~atm}\right)$ and (b) wet condition $\left(\mathrm{pH}_{2} \mathrm{O}=0.0063 \mathrm{~atm}\right)$.

For typically known BCY-BZY proton conductor materials, non-linear thermal expansion properties have been reported within specific temperature ranges for each condition ${ }^{19,21,22}$. In particular, Lvagaeva et al. ${ }^{23}$ reported that the TEC of the $\mathrm{BCY}$ proton conductor between $600-800^{\circ} \mathrm{C}$ showed a drastic change, similar to the alteration in the concentrations of charge carriers in this work. Consequently, the sudden variations of concentrations in particular temperature regions may have affected the expansion of the specimen. From this result regarding the concentration of charge carriers, the concentrations of holes and protons have low values at high temperatures, coinciding with the reason for the vanishing two-fold relaxation profile with increasing temperature, as mentioned above.

Figure 3 shows the generated proton concentration with decreasing temperature (A-line), the proton concentration caused by the weight difference between the dry $\left(p \mathrm{H}_{2} \mathrm{O}=4.0 \times 10^{-5} \mathrm{~atm}\right)$ and wet $\left(p \mathrm{H}_{2} \mathrm{O}=0.0063 \mathrm{~atm}\right)$ conditions (B-line), and the difference of proton concentration between the A- and B-lines (C-line). Because the $\mathrm{C}$-line shows the difference of proton concentration between the existing protons in the oxide and the protons that can enter the sample when the dry condition is changed to a wet condition, the C-line value indicates the proton concentration remaining in the specimen. Examining the variation in proton concentration with decreasing temperatures in the wet condition in the curve of the A-line, the proton concentration in the sample increases steadily as the temperature decreases to reach the value of 0.055 ; this is maintained at low temperatures. In the B-line curve, the part with constant proton concentration in the initial low-temperature region (below $400^{\circ} \mathrm{C}$ ) is caused by the slow reaction rate from the low temperature; the proton concentration is increased by thermal excitation in the middle temperature $\left(400-600^{\circ} \mathrm{C}\right)$ region. The proton concentration tends to decrease with the decreasing solubility of protons, which occurs in the specimen over $600^{\circ} \mathrm{C}$. This phenomenon is similar to that reported previously ${ }^{24}$, in which it was interpreted as the free-moving protons (trap-free) and those trapped in the specimen for the $\mathrm{Y}$-doped $\mathrm{BaZrO}_{3-\delta}$ proton conductor. The thermodynamically predicted proton concentration is equal to the amount of protons generated by the dry-wet change in each temperature range, because the hydration reaction proceeds at a sufficiently high rate in the high-temperature zone above $800^{\circ} \mathrm{C}$ as shown in the A- and B-line curves in Fig. 3. However, the amount of protons remaining in the specimen increases at lower 


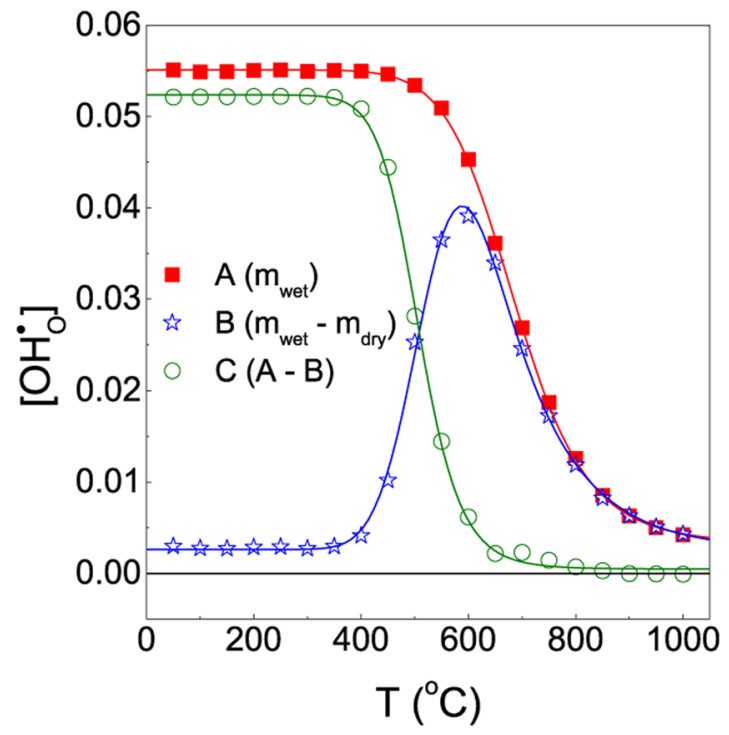

Figure 3. Generated proton concentration under wet condition (A-line), proton concentration caused by condition between dry and wet (B-line), and difference of proton concentration between A- and B- line (C-line).
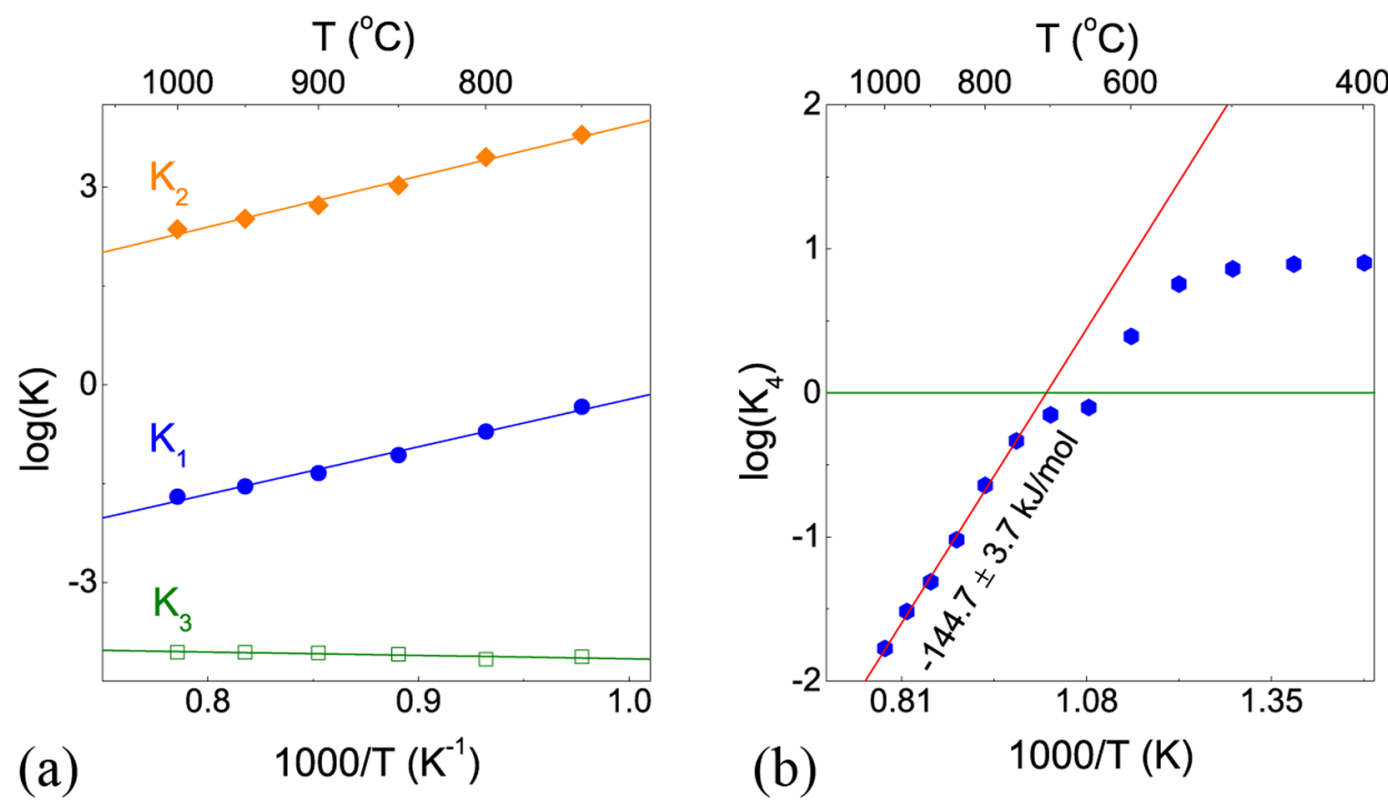

Figure 4. Equilibrium constants $(\mathbf{a})$ of $\mathrm{K}_{1}, \mathrm{~K}_{2}$, and $\mathrm{K}_{3}$ reactions and $(\mathbf{b})$ of $\mathrm{K}_{4}$ reactions.

temperatures because of the increasing difference between the A- and B-line proton concentrations. Because the protons in trapped state cannot escape the specimen with decreases in temperature, the protons may accumulate in the oxide.

Equilibrium constant of hydration reactions. Figure $4 \mathrm{a}$ shows each reaction equilibrium constants for the high-temperature region $\left(750-1000^{\circ} \mathrm{C}\right)$. For $K_{1}$ reaction, dehydration occurs above the $700^{\circ} \mathrm{C}$ boundary. For $K_{2}$, the reaction to produce protons is predominant in the range of measured temperatures, but the hole concentration generated by the $K_{2}$ reaction is small because of the relatively trivial proton concentration in the high-temperature region. The reduction reaction is dominant in the $K_{3}$ reaction. Reviewing the overall reaction $\left(K_{4}\right)$ by combining $K_{1}$ and $K_{2}$, as seen in Fig. 4 b, the dehydration reaction dominates at temperatures above $\sim 600^{\circ} \mathrm{C}$; in contrast, hydration dominates at temperatures below $\sim 600^{\circ} \mathrm{C}$ under $p \mathrm{H}_{2} \mathrm{O}=0.0063$ atm and $p \mathrm{O}_{2}=0.1 \mathrm{~atm}$. These results showed the same results mentioned above: the maximum solubility by hydration is shown at $600{ }^{\circ} \mathrm{C}$ as the maximum weight change, and the solubility of water vapor is decreased with increasing temperature from the boundary of $\sim 600^{\circ} \mathrm{C}$. The enthalpy and entropy are compared to literature reports ${ }^{6,7,25-29}$ in Table 1 and these values for $K_{1}$ appear to be reasonable when compared with the entropies and enthalpies of 


\begin{tabular}{|l|l|l|l|l|}
\hline Materials & Type & $\boldsymbol{H}(\mathbf{k J} / \mathbf{m o l})$ & $\boldsymbol{S}(\mathbf{J} / \mathbf{m o l} \cdot \mathbf{K})$ & References \\
\hline $\mathrm{BaCe}_{0.9} \mathrm{Y}_{0.1} \mathrm{O}_{3-\delta}$ & $K_{I}$ & $-138.0 \pm 6.9$ & $-142.2 \pm 6.1$ & This work* \\
\hline $\mathrm{BaCe}_{0.9} \mathrm{Y}_{0.1} \mathrm{O}_{3-\delta}$ & $K_{2}$ & $-147.8 \pm 8.2$ & $-72.4 \pm 7.2$ & This work* \\
\hline $\mathrm{BaCe}_{0.9} \mathrm{Y}_{0.1} \mathrm{O}_{3-\delta}$ & $K_{3}$ & $9.8 \pm 3.0$ & $-69.8 \pm 2.6$ & This work* \\
\hline $\mathrm{BaCe}_{0.9} \mathrm{Y}_{0.1} \mathrm{O}_{3-\delta}$ & $K_{4}$ & $-144.7 \pm 3.7$ & $-147.8 \pm 3.2$ & This work* \\
\hline $\mathrm{BaCe}_{0.9} \mathrm{Y}_{0.1} \mathrm{O}_{3-\delta}$ & $K_{I}$ & -122 & -119 & 28 \\
\hline $\mathrm{BaCe}_{0.9} \mathrm{Y}_{0.1} \mathrm{O}_{3-\delta}$ & $K_{I}$ & -163.3 & -167.9 & 6 \\
\hline $\mathrm{BaCe}_{0.9} \mathrm{Y}_{0.1} \mathrm{O}_{3-\delta}$ & $K_{I}$ & -123 & -113 & 29 \\
\hline $\mathrm{BaCe}_{0.9} \mathrm{Yb}_{0.1} \mathrm{O}_{3-\delta}$ & $K_{I}$ & -127 & -126 & 28 \\
\hline $\mathrm{BaCe}_{0.6} \mathrm{Zr}_{0.3} \mathrm{Y}_{0.1} \mathrm{O}_{3-\delta}$ & $K_{I}$ & -106 & -104 & 29 \\
\hline $\mathrm{BaCe}_{0.2} \mathrm{Zr}_{0.7} \mathrm{Y}_{0.1} \mathrm{O}_{3-\delta}$ & $K_{I}$ & -93 & -96 & 29 \\
\hline $\mathrm{BaZr}_{0.9} \mathrm{Y}_{0.1} \mathrm{O}_{3-\delta}$ & $K_{I}$ & -79.5 & -88.9 & 6 \\
\hline $\mathrm{BaZr}_{0.9} \mathrm{Y}_{0.1} \mathrm{O}_{3-\delta}$ & $K_{I}$ & -83.3 & -91.2 & 29 \\
\hline $\mathrm{SrCe}_{0.95} \mathrm{Eu}_{0.05} \mathrm{O}_{3-\delta}$ & $K_{I}$ & -164 & - & 26 \\
\hline $\mathrm{SrCe}_{0.95} \mathrm{Yb}_{0.05} \mathrm{O}_{3-\delta}$ & $K_{I}$ & -157 & -128 & 7 \\
\hline $\mathrm{SrTi}_{0.98} \mathrm{Sc}_{0.02} \mathrm{O}_{3-\delta}$ & $K_{I}$ & -21.7 & -97.5 & 6 \\
\hline $\mathrm{Ba}_{3} \mathrm{Ca}_{1.17} \mathrm{Nb}_{1.83} \mathrm{O}_{9-\delta}$ & $K_{I}$ & -65.2 & -103.7 & 6 \\
\hline $\mathrm{Ba}_{3} \mathrm{Ca}_{1.18} \mathrm{Nb}_{1.82} \mathrm{O}_{9-\delta}$ & $K_{I}$ & -78.5 & -111 & 27 \\
\hline $\mathrm{Ba}_{0.5} \mathrm{Sr}_{0.5} \mathrm{Fe}_{0.8} \mathrm{Zn}_{0.2} \mathrm{O}_{3-\delta}$ & $K_{I}$ & -70 & -150 & 25 \\
\hline $\mathrm{Ba}_{2} \mathrm{YSnO}_{5.5}$ & $K_{I}$ & -79.9 & -108.8 & 6 \\
\hline & & & & \\
\hline
\end{tabular}

Table 1. The equilibrium constants for each reaction in high-temperature region $\left(750-1000^{\circ} \mathrm{C}\right)$. $*$ The value of "This work" is calculated with temperature range of $1000-750^{\circ} \mathrm{C}$.

similar materials. The newly extracted enthalpy and entropy of the $K_{4}$ reaction are shown as $-144.7 \pm 3.7 \mathrm{~kJ} / \mathrm{mol}$ and $-147.8 \pm 3.2 \mathrm{~J} / \mathrm{mol} \cdot \mathrm{K}$, respectively.

As shown in Fig. 2, the proton concentration decreases with temperature above $500{ }^{\circ} \mathrm{C}$, suggesting exothermic reaction with negative activation energy of $K_{1}, K_{2}$, and $K_{4}$ at given in Fig. 4 , which is the very general trend of proton conducting perovskites. On the contrary, positive oxidation enthalpy in Fig. 4 was expected from the increase of oxygen vacancy concentration at temperature above $750^{\circ} \mathrm{C}$ in Fig. 2, leading to endothermic oxidation reaction. This results are opposite to the DFT calculation that the exothermic oxidation reaction may be unfavorable at high temperature while favored at low temperature ${ }^{30}$. However, one should note another recent report saying that the sign of oxidation enthalpy may be influenced by the deep acceptor levels of wide-band-gap acceptor-doped perovskites ${ }^{31}$. The further discussion regarding the oxidation enthalpy contribution involving from cerium oxidation variation and/or acceptor levels within band gap should be discussed with more systematic data in future.

\section{Conclusions}

A mass relaxation experiment on $\mathrm{Y}$-doped $\mathrm{BaCeO}_{3}$ was performed below $1000^{\circ} \mathrm{C}$ in the $p$-type regime to understand clearly the phenomenon of decoupled hydrogen and oxygen, which causes the two-fold conductivity relaxation profile. The decoupled ions participated in hydration/dehydration reactions were proven to be at different ratios from the result introduced by the $8 R_{m}$ function, depending on the thermodynamic conditions. Oxygen species were more involved than hydrogen from water in the oxide between $600-700{ }^{\circ} \mathrm{C}$, while hydrogen was slightly active to excess above $750-900^{\circ} \mathrm{C}$ in the hydration reaction. In the weight difference between the dry and wet conditions, the total weight change in the wet condition was lower than that in the dry condition, indicating that protons absorbed in the wet condition remained in the oxide as the temperature decreased. Therefore, the proton concentration tended to converge at low temperatures to reach a value of 0.055 at $p \mathrm{H}_{2} \mathrm{O}=0.0063$ atm and $\mathrm{pO}_{2}=0.1 \mathrm{~atm}$. Each reaction equilibrium constant was calculated in the high-temperature region of $750-1000^{\circ} \mathrm{C}$; the enthalpy and entropy of the nonstoichiometric hydration reaction are $-144.7 \pm 3.7 \mathrm{~kJ} / \mathrm{mol}$ and $-147.8 \pm 3.2 \mathrm{~J} /$ $\mathrm{mol} \cdot \mathrm{K}$, respectively.

\section{Method}

Sample preparation. Polycrystalline $\mathrm{BaCe}_{0.9} \mathrm{Y}_{0.1} \mathrm{O}_{3-\delta}$ (BCY10) powders were prepared by a solid-state reaction method, with $\mathrm{BaCO}_{3}$ (purity 99.99\%), $\mathrm{CeO}_{2}$ (purity 99.99\%), and $\mathrm{Y}_{2} \mathrm{O}_{3}$ (purity 99.99\%) used as starting materials, purchased from Alfa Aesar and Sigma Aldrich. The starting materials were mixed in stoichiometric amounts and ball-milled with stabilized zirconia balls and isopropyl alcohol for $24 \mathrm{~h}$. The mixed powder was dried in an oven at $80^{\circ} \mathrm{C}$ for $10 \mathrm{~h}$ and the mixture was subsequently calcined at $1300^{\circ} \mathrm{C}$ in air for $10 \mathrm{~h}$ to get BCY 10 . The calcined BCY10 was planetary ball-milled with stabilized zirconia balls and isopropyl alcohol at $300 \mathrm{rpm}$ for $4 \mathrm{~h}$ in order to obtain a fine powder by crushing large-sized particles. The calcined powder was molded into a bar, cold-pressed isostatically at $150 \mathrm{MPa}$, and sintered at $1600^{\circ} \mathrm{C}$ for $10 \mathrm{~h}$ in air atmosphere after covering with same powder. The sintered sample was cut by a low-speed saw into a rectangular parallelepiped specimen. A polisher was used to control the evenness to a level below $1 \mu \mathrm{m}$ using various sandpapers and chemical abrasives. The sizes of the samples used for the mass relaxation and two-fold relaxation experiments were $0.42 \times 0.54 \times 0.58 \mathrm{~cm}^{3}$ (weight $=0.7944 \mathrm{~g}$ ) and $0.24 \times 0.24 \times 1.49 \mathrm{~cm}^{3}$, respectively. 
Thermogravimetric analysis measurement. Before the TGA measurements, the specimen was baked under flowing dry gas for $24 \mathrm{~h}$ at $1000^{\circ} \mathrm{C}$ to fully remove the guest protons which can be present in oxides. The dry gas was passed through a coiled cold trap zone of about $1 \mathrm{~m}$ in length to thoroughly remove any water vapor present in the gas. The change in weight was monitored during the baking process; the weight maintained a constant value for $10 \mathrm{~h}$ within the resolution range $( \pm 1 \mu \mathrm{g})$ of the TGA apparatus. After baking, measurement was performed for decreasing temperatures in steps of $50^{\circ} \mathrm{C}$ from $1000^{\circ} \mathrm{C}$. Wet-condition baking was performed by flowing wet gas $\left(\mathrm{H}_{2} \mathrm{O}=6.3 \times 10^{-3} \mathrm{~atm}\right)$ for $10 \mathrm{~h}$ while monitoring the weight of the specimen till the weight becomes constant within the resolution range of the TGA equipment. After this determination, the experiment was performed under the same temperature step conditions as in the dry case $\left(p \mathrm{H}_{2} \mathrm{O}=4.0 \times 10^{-5}\right.$ atm $)$. During this experiment, when all given conditions were fixed excepting temperature, the analysis of weight change as a function of time can be difficult to interpret in low-temperature range because the reaction rate related to the weight change quantity, is lower at the lower temperatures. Therefore, to minimize the error from the lower reaction rate, a stabilization process are performed by holding the sample, at lower temperatures (below $700^{\circ} \mathrm{C}$ ), for $\sim 10-100 \mathrm{~h}$ and, at high temperatures (exceeding $700^{\circ} \mathrm{C}$ ), for $\sim 2-10 \mathrm{~h}$.

\section{References}

1. Song, S.-J., Moon, J.-H., Lee, T. H., Dorris, S. E. \& Balachandran, U. Thickness dependence of hydrogen permeability for $\mathrm{Ni}-\mathrm{BaCe}_{08} \mathrm{Y}_{02} \mathrm{O}_{3-\delta}$. Solid State Ion. 179, 1854-1857 (2008).

2. Tomita, A. et al. Chemical and redox stabilities of a solid oxide fuel cell with $\mathrm{BaCe}_{0.8} \mathrm{Y}_{0.2} \mathrm{O}_{3-\alpha}$ functioning as an electrolyte and as an anode. Solid State Ion. 177, 2951-2956 (2006).

3. Zunic, $\mathrm{M}$. et al. Influence of the ratio between $\mathrm{Ni}$ and $\mathrm{BaCe}_{0.9} \mathrm{Y}_{0.1} \mathrm{O}_{3-\delta}$ on microstructural and electrical properties of proton conducting $\mathrm{Ni}-\mathrm{BaCe}_{0.9} \mathrm{Y}_{0.1} \mathrm{O}_{3-\delta}$ anodes. J. Alloy. Compd. 509, 1157-1162 (2011).

4. Haile, S. M. \& Pintauro, P. N. Proton transport for fuel cells. J. Mater. Chem. 20, 6211-6213 (2010).

5. Yamazaki, Y., Hernandez-Sanchez, R. \& Haile, S. M. High Total Proton Conductivity in Large-Grained Yttrium-Doped Barium Zirconate. Chem. Mater. 21, 2755-2762 (2009).

6. Kreuer, K. D. Proton-Conducting Oxides. Annu. Rev. of Mater. Res. 33, 333-359 (2003).

7. Krug, F., Schober, T. \& Springer, T. In situ measurements of the water uptake in $\mathrm{Yb}_{\text {doped }} \mathrm{SrCeO}_{3}$. Solid State Ion. 81, 111-118 (1995).

8. Yamazaki, Y., Yang, C.-K. \& Haile, S. M. Unraveling the defect chemistry and proton uptake of yttrium-doped barium zirconate. Scr. Mater. 65, 102-107 (2011)

9. Schober, T. \& Friedrich, J. Chemical Diffusion of Water in the High-Temperature Proton Conductor $\mathrm{Ba}_{3} \mathrm{Ca}_{1.18} \mathrm{Nb}_{1.82} \mathrm{O}_{9-\delta}$. Ionics 3 , 52-55 (1997)

10. Schober, T., Friedrich, J., Triefenbach, D. \& Tietz, F. Dilatometry of the high-temperature proton conductor $\mathrm{Ba}_{3} \mathrm{Ca}_{1.18} \mathrm{Nb}_{1.82} \mathrm{O}_{9-\delta}$. Solid State Ion. 100, 173-181 (1997).

11. Kreuer, K. D., Schönherr, E. \& Maier, J. Proton and Oxygen diffusion in $\mathrm{BaCeO}_{3}$ based compound: A combined thermal gravimetric analysis and conductivity study. Solid State Ion. 70-71, 278-284 (1994).

12. Yoo, H.-I., Kim, J.-K. \& Lee, C.-E. Electrical Conductivity Relaxations and Chemical Diffusivities of $\mathrm{BaCe}_{0.95} \mathrm{Yb}_{0.05} \mathrm{O}_{2.975}$ upon Hydration and Oxidation. J. Electrochem. Soc. 156, B66-B73 (2009).

13. Yoo, H.-I., Yeon, J. I. \& Kim, J.-K. Mass relaxation vs. electrical conductivity relaxation of a proton conducting oxide upon hydration and dehydration. Solid State Ion. 180, 1443-1447 (2009).

14. Lim, D.-K. et al. Experimental evidence of hydrogen-oxygen decoupled diffusion into $\mathrm{BaZr}_{0.6} \mathrm{Ce}_{0.25} \mathrm{Y}_{0.15} \mathrm{O}_{3-\delta}$. Acta Mater. 61, 1274-1283 (2013).

15. Yu, J. H., Lee, J.-S. \& Maier, J. Peculiar nonmonotonic water incorporation in oxides detected by local in situ optical absorption spectroscopy. Angew. Chem. Int. Ed. Engl. 46, 8992-8894 (2007).

16. Yoo, H.-I., Yoon, J.-Y., Ha, J.-S. \& Lee, C.-E. Hydration and oxidation kinetics of a proton conductor oxide, $\operatorname{SrCe}_{0.95} \mathrm{Yb}_{0.05} \mathrm{O}_{2.975}$. Phys. Chem. Chem. Phys. 10, 974-982 (2008).

17. Uchida, H., Yoshikawa, H. \& Iwahara, H. Formation of protons in $\mathrm{SrCeO}_{3}$-based proton conducting oxides. Part I. Gas evolution and absorption in doped $\mathrm{SrCeO}_{3}$ at high temperature. Solid State Ion. 34, 103-110 (1989).

18. Kreuer, K. D. On the development of proton conducting materials for technological applications. Solid State Ion. 97, 1-15 (1997).

19. Andersson, A. K. E., Selbach, S. M., Knee, C. S. \& Grande, T. Chemical Expansion Due to Hydration of Proton-Conducting Perovskite Oxide Ceramics. J. Am. Ceram. Soc. 97, 2654-2661 (2014).

20. Oishi, M. et al. Oxygen nonstoichiometry of the perovskite-type oxides $\mathrm{BaCe}_{0.9} \mathrm{M}_{0.1} \mathrm{O}_{3-\delta}(\mathrm{M}=\mathrm{Y}, \mathrm{Yb}, \mathrm{Sm}, \mathrm{Tb}$, and $\mathrm{Nd})$. Solid State Ion. 179, 529-535 (2008).

21. Hiraiwa, C. et al. Chemical Expansion and Change in Lattice Constant of Y-Doped $\mathrm{BaZrO}_{3}$ by Hydration/Dehydration Reaction and Final Heat-Treating Temperature. J. Am. Ceram. Soc. 96, 879-884 (2013).

22. Yamaguchi, S. \& Yamada, N. Thermal lattice expansion behavior of Yb-doped $\mathrm{BaCeO}_{3}$. Solid State Ion. 162-163, $23-29$ (2003).

23. Lyagaeva, Y. G. et al. Thermal expansion of materials in the barium cerate-zirconate system. Phys. Solid State 57, 285-289 (2015).

24. Yamazaki, Y. et al. Proton trapping in yttrium-doped barium zirconate. Nat. Mater. 12, 647-651 (2013).

25. Poetzsch, D., Merkle, R. \& Maier, J. Proton conductivity in mixed-conducting BSFZ perovskite from thermogravimetric relaxation. Phys. Chem. Chem. Phys. 16, 16446-16453 (2014).

26. Song, S.-J., Wachsman, E. D., Dorris, S. E. \& Balachandran, U. Electrical Properties of p-Type Electronic Defects in the Protonic Conductor $\mathrm{SrCe}_{0.95} \mathrm{Eu}_{0.05} \mathrm{O}_{3-\delta}$. J. Electrochem. Soc. 150, A790-A795 (2003).

27. Krug, F. \& Schober, T. The high-temperature proton conductor $\mathrm{Ba}_{3}\left(\mathrm{Ca}_{1.18} \mathrm{Nb}_{1.82}\right) \mathrm{O}_{9-\mathrm{gd}}$ : Thermogravimetry of the water uptake. Solid State Ion. 92, 297-302 (1996).

28. Oishi, M. et al. Defect structure analysis of B-site doped perovskite-type proton conducting oxide $\mathrm{BaCeO}_{3} \mathrm{Part}_{1}$ : The defect concentration of $\mathrm{BaCe}_{0.9} \mathrm{M}_{0.1} \mathrm{O}_{3-\delta}(\mathrm{M}=\mathrm{Y}$ and $\mathrm{Yb})$. Solid State Ion. 180, 127-131 (2009).

29. Ricote, S., Bonanos, N. \& Caboche, G. Water vapour solubility and conductivity study of the proton conductor $\mathrm{BaCe}_{(0.9-x)} \mathrm{Zr}_{\mathrm{x}} \mathrm{Y}_{0.1} \mathrm{O}_{(3-\delta)}$. Solid State Ion. 180, 990-997 (2009).

30. Hermet, J., Bottin, F., Dezanneau, G. \& Geneste, G. Thermodynamics of hydration and oxidation in the proton conductor Gd-doped barium cerate from density functional theory calculations. Phys. Rev. B 85, 205137 (2012).

31. Putilov, L. P. \& Tsidilkovski, V. I. The role of deep acceptor centers in the oxidation of acceptor-doped wide-band-gap perovskites $\mathrm{ABO}_{3}$. J. Solid State Chem. 247, 147-155 (2017).

\section{Acknowledgements}

This work was supported by Mid-Career Researcher Program (2015R1A2A2A01003852) through NRF grant funded by the MEST. 


\section{Author Contributions}

H.-I.Y. and S.-J.S. conceptualized the study. D.-K.L. and H.-N.I. carry out the experiments and calculations. All members discussed the results. D.-K.L. prepared figures and table. D.-K.L. and S.-J.S. wrote the main manuscript and all members reviewed the manuscript.

\section{Additional Information}

Supplementary information accompanies this paper at doi:10.1038/s41598-017-00595-W

Competing Interests: The authors declare that they have no competing interests.

Publisher's note: Springer Nature remains neutral with regard to jurisdictional claims in published maps and institutional affiliations.

(c) (i) This work is licensed under a Creative Commons Attribution 4.0 International License. The images or other third party material in this article are included in the article's Creative Commons license, unless indicated otherwise in the credit line; if the material is not included under the Creative Commons license, users will need to obtain permission from the license holder to reproduce the material. To view a copy of this license, visit http://creativecommons.org/licenses/by/4.0/

(c) The Author(s) 2017 